\title{
Effect of flowering promotion with NAA or ethephon on 'Golden Delicious' apple trees with different flowering intensities
}

\author{
J. Hladnik and M. Stopar \\ Department of Fruit Growing, Viticulture and Oenology, Agricultural Institute of Slovenia, Ljubljana, Slovenia
}

\section{Summary}

Heavy cropping causes low-quality fruit and can lead to the biennial bearing pattern in the apple (Malus $\times$ domestica Borkh.). To make fruit production more sustainable, chemical thinning and flowering-promotion chemicals are used to reduce crop load and promote flower-bud formation in years when flowering is abundant.

In this paper, the results of return bloom (RB) enhancement with five summer weekly applications of $5 \mathrm{mg} \mathrm{L}^{-1}$ naphthaleneacetic acid (NAA) or $100 \mathrm{mg} \mathrm{L}^{-1}$ ethephon to promote flowering are presented. Treated 'Golden Delicious' apple trees with a low, medium and high flowering intensity were previously thinned with ammonium thiosulphate (ATS), naphthaleneacetamide (NAD), NAA or 6-benzyladenine (BA), or left unthinned. Thinned and unthinned highly flowering trees had twice as much fruit at harvest and at least 6 times fewer flowers per tree in RB if trees were not treated with flowering-promotion chemicals. Five summer NAA or ethephon applications significantly improved RB in medium and highly flowering trees in all the experiments. However, in some experiments over-thinning and excessive RB flowering was observed on trees with a low flowering intensity, especially with five summer ethephon applications.

Additionally, an NAA concentration-response study was performed on 'Fuji', 'Red Delicious', 'Golden Delicious' and 'Elstar' to assess NAA flowering-promotion and the fruitlet-retention effect on these cultivars. NAA applications were linearly correlated to RB enhancement on all the cultivars except 'Red Delicious'. However, NAA concentration was linearly correlated to the number of small fruits retained on 'Fuji', 'Elstar', and particularly 'Red Delicious' trees.

\section{Keywords}

flower-bud formation, fruit-set, heterogeneity, overthinning, pygmy fruits, return bloom, snowball-flowering

\section{Introduction}

Biennial bearing is a common issue in commercial apple production, characterised by unbalanced flowering and fruit production in different years and for individual trees. To reduce the biennial bearing pattern and make apple production more sustainable, thinning of flowers or fruitlets and application of flowering-promotion chemicals are commonly used in years with intensely flowering trees (Ferree, 1992; Tromp,

\section{Significance of this study}

What is already known on this subject?

- Besides thinning, flowering promoting treatments are needed to enhance return bloom (RB) and stabilise apple production from year to year in commercial apple orchards.

What are the new findings?

- A response to summer NAA or ethephon applications is characterised for 'Golden Delicious' trees with different pre-treatments and flowering intensities.

What is the expected impact on horticulture?

- Gained knowledge supports the preparation of orchards spraying programmes and can be integrated with algorithms for selective spraying to prevent biennial bearing.

2000; Stopar, 2004; Kon and Schupp, 2018). Although flower or fruitlet thinning measures are generally applied to improve fruit size and quality, they also have an influence on return bloom (RB). However, on chemically-thinned, highly flowering apple trees RB enhancement is usually not sufficient to satisfy yield expectations for the next season. Some chemical-thinning agents such as naphthaleneacetic acid (NAA) and ethephon have been shown to have a noticeable influence on RB even if applied later in the growing season, and their enhancement of RB exceeded what could be expected from their thinning effect alone (Trump, 2000; Bukovac et al., 2006; McArtney and Unrath, 2006). McArtney et al. (2013) showed that summer NAA applications have a flowering-promotion effect if applied up to pre-harvest time. This may only be true on trees with moderate flowering activity and in climates where shoot growth typically continues over a long period (McArtney et al., 2007). Nevertheless, caution with NAA application is needed, due to possibility of reduced fruit growth and small fruit retention, especially when combined with other thinning agents like BA (Jones et al., 1991; Bukovac et al., 1994; Stopar and Tojnko, 2005). Thinning and a flowering-promotion effect similar to NAA has also been proven for ethephon (Schmidt et al., 2009; McArtney et al., 2013). Summer ethephon applications reduced the variation in yield between years, when applied in years with a high crop (Bukovac et al., 2006). Both NAA and ethephon have some effect on fruit quality, but the results are inconsistent (McArtney et al., 2007; Cline, 2019).

The response of individual apple trees with different flowering and bearing activity to chemical treatments may 
be crucial for the development of precision agriculture management in the future (Krasniqi et al., 2013). The recent development of specific agricultural technology has led to machines able to tackle the heterogeneity of orchards and treat individual trees according to their physiological status (Hong et al., 2012; Hočevar et al., 2014). However, to develop effective sensing and decision-making algorithms, extensive real-life knowledge is needed.

The primary objective of this study was to evaluate the effect of NAA or ethephon as flowering-promotion agents on the number of fruits at harvest and on RB of 'Golden Delicious' trees previously selected to three different flowering intensity groups in springtime. These flowering-promotion chemicals were applied to i) non-thinned and ii) previously chemically thinned trees with four standard thinning agents, to explore possible interactions between thinning and flowering-promotion agents. Additionally, iii) an NAA concentration-response study was performed on four apple cultivars to address fruit growth retardation effect following NAA application.

\section{Materials and methods}

All the experiments were conducted at the Brdo pri Lukovici experimental orchard (continental Slovenia; $46^{\circ} 10^{\prime} 04.8^{\prime \prime} \mathrm{N}, 14^{\circ} 40^{\prime} 55.2^{\prime \prime} \mathrm{E}$ ) in growing seasons from 2010 to 2015 . The 15-ha orchard has relatively uniform semiheavy soil and micro-climatic conditions with average yearly temperature of $10^{\circ} \mathrm{C}$ and $1,200 \mathrm{~mm}$ of precipitation. The experiments were performed on mature apple trees grown on M. 9 rootstock with the slender spindle training system. The experiments were set out in a randomised complete block design, with six blocks arranged in one or two rows of trees with uniform vigour and appropriate flowering intensity in the spring. The number of flower clusters per individual tree was counted at the beginning of flowering time in the current year and the following year to estimate RB. The fruit was picked at technological ripeness, graded by fruit diameter size above or below $70 \mathrm{~mm}$ and counted. The number of fruits below $45 \mathrm{~mm}$ was also estimated if present in abundance. All the spraying treatments were applied to single-tree plots with a knapsack sprayer until to the point of drip.

Six experiments were performed to evaluate the influence of flowering-promotion NAA and ethephon applications in summer on the fruit-set and RB of 'Golden Delicious' trees. Before flowering, the trees were divided into low (L), medium (M) or high (H) flowering-intensity classes with 20-50, 70-120 and 150-250 flower clusters per tree, respectively. Summer NAA and ethephon treatments were performed on trees from all flowering-intensity classes, with five weekly applications starting four weeks after full bloom. NAA (Dirager, L. Gobbi S.r.l., Campo Ligure, Italy) or ethephon (Flordimex, Nufarm Polska Sp. Z o.o., Warsaw, Poland) was applied at a 5 or $100 \mathrm{mg} \mathrm{L}^{-1}$ concentration, respectively. This flowering-promotion applications pattern, as reported by McArtney et al. (2007) with a few modifications, is in this paper referred to as summer NAA or ethephon applications.

In the first two experiments (Experiments 1 and 2 in 2011 and 2010, respectively; Table 1) the 'Golden Delicious' trees were not thinned and the treatments were: a) control - untreated, b) flowering promotion with NAA, and c) flowering promotion with ethephon. In the second set of experiments (Experiments 3, 4, 5 and 6 in 2012, 2013, 2014 and 2016, respectively; Table 2), previous thinning of 'Golden Delicious' trees was performed with $0.7 \%(\mathrm{w} / \mathrm{w})$ ammonium thiosulphate (ATS; AGRO N Fluid, TIB Chemicals AG, Mannheim, Germany) at full bloom; $100 \mathrm{mg} \mathrm{L}^{-1}$ naphthaleneacetamide (NAD; Amid Thinn, ISAGRO S.p.A., Milan, Italy) at the end of flowering; $12 \mathrm{mg} \mathrm{L}^{-1}$ naphthaleneacetic acid (NAA; Dirager, L. Gobbi S.r.l., Campo Ligure, Italy) when the fruitlets reached a diameter of $10 \mathrm{~mm}$; or $100 \mathrm{mg} \mathrm{L}^{-1}$ 6-benzyladenine (BA; MaxCel, Valent BioSciences Co., Libertyville, Illinois, U.S.A.) when the fruitlets reached a $10 \mathrm{~mm}$ diameter. The treatments in this set of experiments were: a) control - untreated, b) thinning, c) thinning + flowering promotion with NAA, and

TABLE 1. Effect of five summer $5 \mathrm{mg} \mathrm{L}^{-1}$ naphthaleneacetic acid (NAA) or $100 \mathrm{mg} \mathrm{L}^{-1}$ ethephon applications on fruit-set, fruit size and return bloom (RB) on non-thinned 'Golden Delicious' trees with low (L), medium (M) and high (H) flowering intensity.

\begin{tabular}{|c|c|c|c|c|c|c|c|c|c|c|}
\hline & \multicolumn{5}{|c|}{ Experiment 1} & & \multicolumn{4}{|c|}{ Experiment 2} \\
\hline & & $\begin{array}{l}\text { Flower } \\
\text { clusters }\end{array}$ & Fruit & $\begin{array}{c}\text { Fruit } \\
>70 \mathrm{~mm} \\
\end{array}$ & $\mathrm{RB}$ & & $\begin{array}{l}\text { Flower } \\
\text { clusters }\end{array}$ & Fruit & $\begin{array}{c}\text { Fruit } \\
>70 \mathrm{~mm}\end{array}$ & $\mathrm{RB}$ \\
\hline & & no. tree $^{-1}$ & no. tree- ${ }^{-1}$ & no. tree- ${ }^{-1}$ & no. tree $^{-1}$ & & no. tree $^{-1}$ & no. tree ${ }^{-1}$ & no. tree ${ }^{-1}$ & no. tree ${ }^{-1}$ \\
\hline Control & L & 26 & $67 a$ & $51 \mathrm{~b}$ & $274 b$ & L & 42 & $108 \mathrm{a}$ & 57 a & $380 \mathrm{c}$ \\
\hline $5 \times \mathrm{NAA}$ & & 41 & $62 \mathrm{a}$ & $34 \mathrm{~b}$ & $419 a b$ & & 41 & $89 a b$ & 58 a & $440 \mathrm{c}$ \\
\hline $5 \times$ ethephon & & 47 & $71 \mathrm{a}$ & $47 \mathrm{~b}$ & $490 \mathrm{a}$ & & 38 & $67 \mathrm{~b}$ & $53 a$ & $440 \mathrm{c}$ \\
\hline Control & M & 141 & $155 a$ & $54 \mathrm{ab}$ & $26 b$ & M & 102 & $143 b$ & $41 \mathrm{a}$ & $64 \mathrm{c}$ \\
\hline $5 \times \mathrm{NAA}$ & & 126 & $170 \mathrm{a}$ & $66 \mathrm{a}$ & $90 \mathrm{a}$ & & 104 & $135 b$ & $56 \mathrm{a}$ & $165 b$ \\
\hline $5 \times$ ethephon & & 111 & $155 a$ & $34 \mathrm{~b}$ & $64 \mathrm{ab}$ & & 96 & $114 \mathrm{~b}$ & $39 a$ & $306 a$ \\
\hline Control & H & 195 & $229 a$ & $46 \mathrm{~b}$ & $31 \mathrm{~b}$ & $\mathrm{H}$ & 194 & $208 a$ & $69 a$ & $34 \mathrm{c}$ \\
\hline $5 \times \mathrm{NAA}$ & & 221 & $193 a$ & $87 a$ & $62 \mathrm{a}$ & & 203 & $185 a b$ & $51 \mathrm{a}$ & $128 b$ \\
\hline $5 \times$ ethephon & & 199 & $188 \mathrm{a}$ & $44 \mathrm{~b}$ & $51 \mathrm{ab}$ & & 202 & $146 \mathrm{~b}$ & $52 \mathrm{a}$ & $203 a$ \\
\hline \multicolumn{11}{|l|}{ Significance } \\
\hline Flowering intensity & & & $* * *$ & NS & $* * *$ & & & *** & NS & *** \\
\hline Chemicals & & & NS & * & NS & & & $* * *$ & NS & $* * *$ \\
\hline Interaction & & & NS & $* *$ & NS & & & NS & NS & NS \\
\hline
\end{tabular}

Means with different letters within flowering intensity groups in a column are significantly different at P-value $<0.05$ as determined by Duncan's multiple range tests. ANOVA significance of influences is indicated as NS, ${ }^{*}$, ${ }^{* *}$ and ${ }^{* * *}$ for ANOVA P-values of $>0.05,<0.05,<0.01$ and $<0.001$, respectively. 


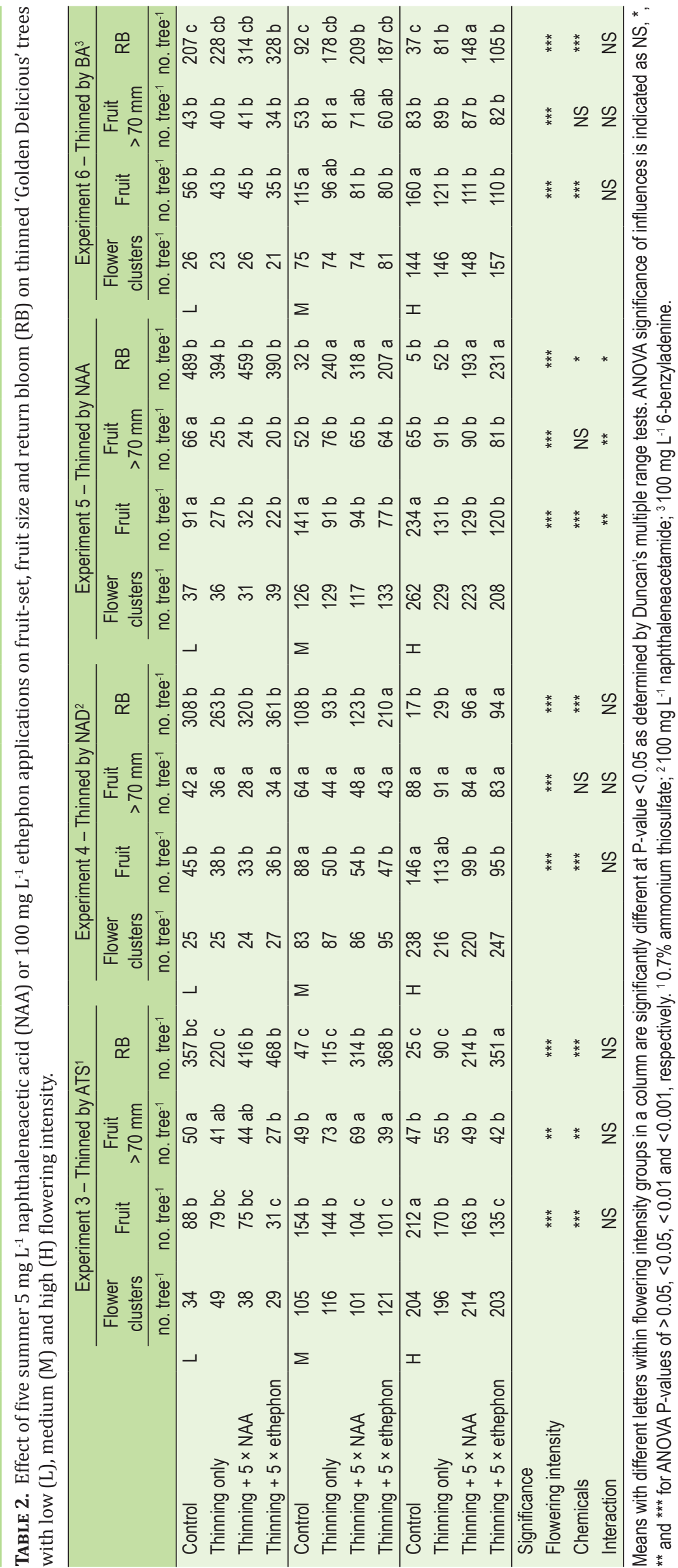




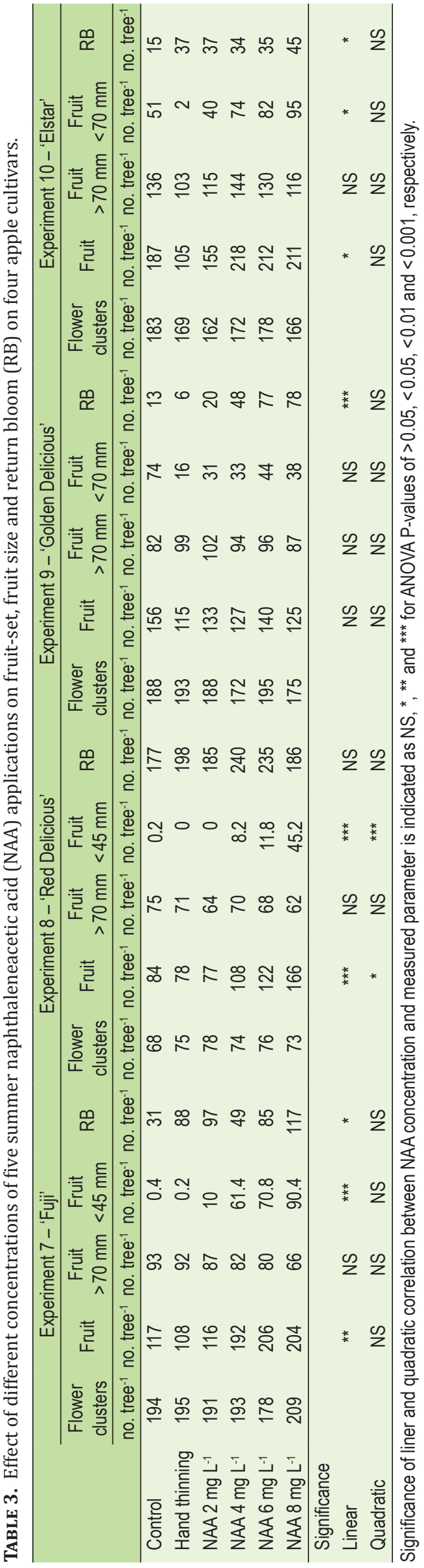

d) thinning + flowering promotion with ethephon.

To evaluate the effect of NAA on fruit growth and RB a concentration-response study was performed on 'Red Delicious', 'Fuji', 'Golden Delicious' and 'Elstar' apple trees in years 2010, 2010, 2014 and 2014, respectively (Experiments 7-10; Table 3). The six treatments in this study were: a) control - untreated, b) hand thinned, c) $2 \mathrm{mg} \mathrm{L}^{-1} \mathrm{NAA}$, d) $4 \mathrm{mg} \mathrm{L}^{-1}$ NAA, e) $6 \mathrm{mg} \mathrm{L}^{-1} \mathrm{NAA}$, and f) $8 \mathrm{mg} \mathrm{L}^{-1} \mathrm{NAA}$. The time pattern for summer NAA applications was the same as for the previous experiments.

Statistical analysis was performed with Statgraphics 16 (Statgraphics Technologies Inc., The Plains, Virginia, U.S.A.). For experiments evaluating flowering promotion with NAA or ethephon on 'Golden Delicious' trees, factorial analysis of variance was performed to determine two main effects: flowering-intensity groups and chemical treatments and their interaction. Means separation, as indicated by different letters within defined flowering-intensity groups in the Tables, was performed using Duncan's multiple range test at $\mathrm{P}=0.05$ (Tables 1 and 2).

For NAA concentration, linear and quadratic correlation trends with fruit-set and RB were calculated (Table 3). For all statistical models, significance in the Tables is presented as NS, *, ** and $* * *$ for P-values of $>0.05,<0.05,<0.01$ and $<0.001$, respectively.

\section{Results}

\section{Flowering promotion with NAA or ethephon applications on non-thinned trees}

Flowering promotion with NAA or ethephon applications in summer was evaluated in two experiments on nonthinned 'Golden Delicious' trees with different flowering-intensity classes ( $\mathrm{L}, \mathrm{M}$ and $\mathrm{H}$; Table 1 ). The flowering-intensity classes had a dominant effect on the number of fruits at harvest and RB. L control trees had 10 times higher RB than $\mathrm{H}$ control trees in both experiments. Summer applications of NAA significantly increased RB on $\mathrm{M}$ and $\mathrm{H}$ trees in both experiments, while applications of ethephon significantly increased $\mathrm{RB}$ of $\mathrm{M}$ and $\mathrm{H}$ trees only in the second experiment, in which it exceeded the effect of NAA. In Figure 1 the relationship between initial flowering intensity and RB flowering is presented for all trees in these two experiments. $\mathrm{L}$ trees responded with higher $\mathrm{RB}$ than $\mathrm{H}$ trees regardless of NAA or ethephon applications. NAA and ethephon had a flowering-promotion effect predominantly on $\mathrm{H}$ trees.

\section{Flowering promotion with NAA or ethephon applications on previously thinned trees}

In experiments in which summer NAA or ethephon was applied to previously thinned 'Golden Delicious' trees, the flowering-intensity classes $(\mathrm{L} / \mathrm{M} / \mathrm{H})$ had the greatest impact on fruit-set and RB (Table 2). Flowering-intensity class also determined the efficacy of the chemicals applied, with thinning and flowering-promotion measures showing a greater impact on trees with high flowering intensity in all four experiments (Figure 2).

Thinning with ATS reduced the number of fruits on $\mathrm{H}$ trees and increased the number of commercially sized fruits on M trees (Experiment 3; Table 2). Summer NAA applications had an additional thinning effect on $M$ trees, while ethephon applications thinned trees from all flowering-intensity classes, leading to an over-thinning effect on L trees. Untreated $\mathrm{H}$ and $\mathrm{M}$ trees had insufficient RB for a regular yield in the following year and thinning with ATS did not im- 
prove RB significantly. Summer applications of NAA or ethephon enhanced RB in all flowering intensity classes, which caused excessive RB flowering in some L trees.

Treatment with NAD significantly thinned only M trees, although a slight decrease in the number of fruits was noticed also in L and $\mathrm{H}$ trees (Experiment 4; Table 2). Summer applications of NAA or ethephon had an insignificant effect on fruit-set, although some additional thinning of $\mathrm{H}$ trees was observed. RB was mainly influenced by flowering intensity classes, with $\mathrm{H}$ control trees having very low RB. Thinning with NAD had no effect on RB, while summer NAA or ethephon applications increased RB on $\mathrm{H}$ trees to acceptable levels, whereas on $\mathrm{M}$ trees only summer ethephon applications significantly increased RB.

Thinning with NAA resulted in a significant decrease in the number of fruits at harvest in all flowering intensity classes, which resulted in over-thinning of $L$ trees (Experiment 5; Table 2). Summer NAA or ethephon applications had no further effect on fruit-set. RB was mainly influenced by flowering intensity classes, with $\mathrm{M}$ and $\mathrm{H}$ control trees having very low RB when untreated. NAA thinning significantly improved RB only on M trees, while both summer NAA and ethephon applications significantly increased RB for $\mathrm{H}$ trees.

Treatment with BA had a thinning effect only on $\mathrm{H}$ trees and following summer NAA or ethephon applications did not influence fruit-set significantly (Experiment 6; Table 2). Thinning with BA caused a slight increase in RB in all flowering intensity classes, but in $\mathrm{H}$ trees it still did not reach levels sufficient to support regular yield. Additional summer NAA applications increased RB on both $\mathrm{H}$ and $\mathrm{M}$ trees. Summer ethephon applications did not further enhance RB compared to the BA thinning treatment alone. In Figure 2 relationship between initial flowering intensity and RB flowering for all trees in Experiments 3-6 (previous chemical thinning) is presented to illustrate the effect of flowering promotion with NAA and ethephon. Chemical thinning had on average no effect on RB while NAA and especially ethephon increased RB in all flowering intensity classes, most intensively in $\mathrm{H}$ trees where RB was very low if trees were not treated.

\section{NAA concentration-response study}

The NAA concentration-response study with summer flowering-promotion applications patterns was carried out for four cultivars ('Fuji', 'Red Delicious', 'Golden Delicious'
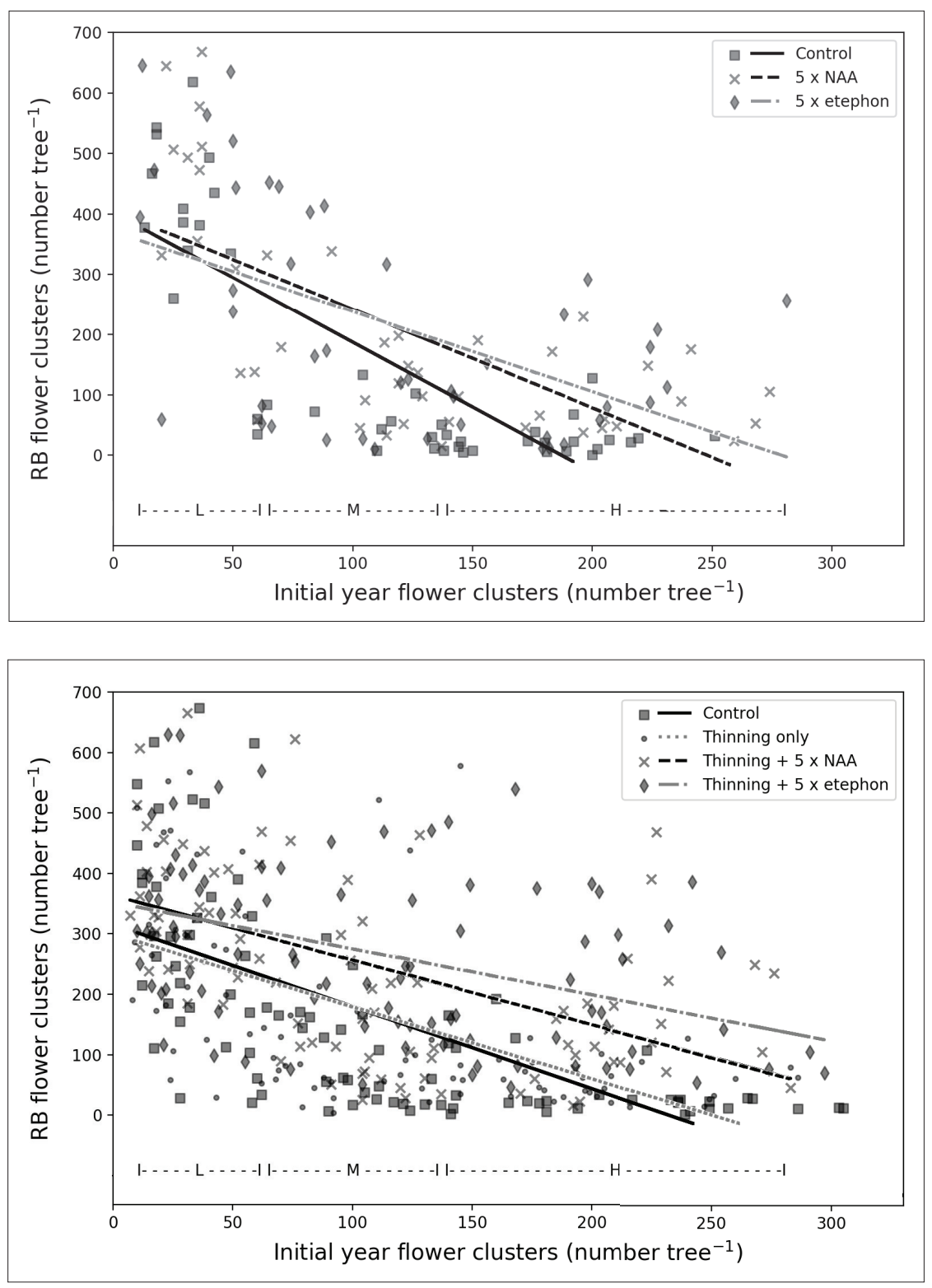

FIGURE 1. Relationship between flower cluster number in the initial year and in subsequent year return bloom (RB) for all trees in Experiments 1 and 2. To illustrate the effect on RB linear regression lines are fitted to chemical treatments Control - non-treated trees, trees treated with five applications of $5 \mathrm{mg} \mathrm{L} \mathrm{L}^{-1}$ naphthaleneacetic acid (NAA) and trees treated with five applications $100 \mathrm{mg} \mathrm{L}^{-1}$ ethephon. Tree flowering-intensity classes L: low, M: medium, and $\mathrm{H}$ : high as used in tables and text are indicated.

FIGURE 2. Relationship between flower cluster number in the initial year and in subsequent year return bloom (RB) for all trees in Experiments 3-6. To illustrate the effect on RB linear regression lines are fitted to chemical treatments Control non-treated trees, trees thinned with different thinning agents (see text), trees additionally treated with five applications of $5 \mathrm{mg} \mathrm{L}^{-1}$ naphthaleneacetic acid (NAA) and trees additionally treated with five applications $100 \mathrm{mg} \mathrm{L}^{-1}$ ethephon. Tree flowering-intensity classes L: low, M: medium and $\mathrm{H}$ : high as used in tables and text are indicated. 
and 'Elstar') to evaluate the effect of NAA on fruit-set, fruit size and RB (Table 3). The concentration of NAA showed a positive linear correlation to the number of fruits at harvest time for 'Elstar', 'Fuji' and especially 'Red Delicious'. The increased number of fruits was a consequence of retention of so-called pygmy fruits $(<45 \mathrm{~mm})$ in 'Fuji' and especially 'Red Delicious', where the number of pygmy fruits had a quadratic correlation to NAA concentration. In contrast, summer NAA applications had no influence on 'Golden Delicious' fruit-set in this experiment (Experiment 9; Table 3). The NAA concentration in summer applications was linearly correlated to RB in 'Fuji', 'Elstar', and particularly 'Golden Delicious', while there was no RB effect on 'Red Delicious'. NAA promotion of RB on 'Fuji' and 'Elstar' only exceeded the effect of hand thinning at the highest NAA concentrations, while on 'Golden Delicious' a continuous increase in RB was observed with increasing NAA concentrations in summer applications.

No additional russet of apple skin caused by flowering-promotion chemicals NAA or ethephon was observed in experiments $1-10$.

\section{Discussion}

Flowering intensity classes had the biggest influence on fruit-set, RB and the efficacy of the applied chemical treatments in all six experiments with differently flowering 'Golden Delicious' trees. These results are in accordance with the dominant influence of flowering intensity on fruit-set and RB described by Embree (2007) and Breen et al. (2016). Control trees with a low flowering intensity had low fruit-set and abundant RB, while trees with a high flowering intensity had high fruit-set but very little RB if untreated. Similar results have been obtained by other authors (Jonkers, 1979; Schmidt et al., 2009; Breen et al., 2016). Both an excessively low and an excessively high flowering intensity are to be avoided to stabilise and maximise production of high-quality fruit.

Thinning and flowering-promotion chemical treatments are mainly needed for trees with a high flowering intensity, where high crop-load prevents fruit growth and sufficient flower-bud formation (Davis, 2004; Kon and Schupp, 2018; Stefanelli et al., 2018). However, sometimes the effect of chemical thinning and flowering promotion was also noticeable in trees with a low flowering intensity, causing over-thinning and/or excessive RB flowering. Over-thinning needs to be avoided since it unnecessary reduces fruit-set at harvest and may cause some physiological disorders of remaining fruits (Stover et al., 2001). Additional promotion of RB in trees with low flowering intensity can enhance their biennial bearing pattern.

In our experiments, thinning with ATS, NAA and BA significantly reduced the number of fruits at harvest on highly flowering trees, but only BA thinning significantly improved $\mathrm{RB}$ on these trees. In many cases thinning alone does not reduce the fruit-overload signal enough to promote flower-bud formation (Goldschmid, 2018). In our experiments on highly flowering trees, no thinning treatment improved RB sufficiently to support commercial crop production. On the other hand, flowering promotion with summer NAA or ethephon applications significantly increased RB on highly flowering trees in all six experiments. These chemical treatments may interfere with fruit-overload signal or enhance cytokinin/carbohydrate signal and thereby promote flowering (Krasniqi et al., 2013; Goldschmid, 2018). It is believed that flower onset occurs in springtime although exact time determination is methodically not yet possible (Samach and Smith, 2013; Milyaev et al., 2018). We can further speculate that proposed application pattern of flowering promotion agents in low concentrations may extend the period of flower induction to early or late summer (McArtney and Unrath, 2006; McArtney et al., 2013).

Flowering promotion with NAA and ethephon does not aim to influence the current year fruit-set (Schmidt et al., 2009; Robinson et al., 2010; McArtney et al., 2013). Nevertheless, summer ethephon applications had considerable thinning effects in Experiment 2 and in combination with ATS thinning (Experiment 4; Table 2) where it was over-thinning trees with low flowering intensity.

The concentration-response study on summer NAA applications revealed sensitivity differences between cultivars as regards fruit growth retardation and RB promotion. 'Elstar', 'Fuji' and especially 'Red Delicious' were sensitive to NAA fruit-growth retardation in our experiments, while 'Golden Delicious' was not. This sensitivity was previously reported for 'Summerred,' 'Fuji' and 'Red Delicious' when NAA was used as thinning agent (Jones et al., 1991; Stopar and Lokar, 2003; Stopar and Tojnko, 2005). It is prominent when NAA is combined with other thinning chemicals like Cytolin and BA (Bound et al., 1991; Bukovac et al., 2008). Our results suggest that the same phenomenon also occurs when smaller, flowering-promotion NAA concentrations are used in summer on 'Fuji', 'Elstar', and especially 'Red Delicious'. RB was promoted by summer NAA applications on 'Elstar', 'Fuji', and especially 'Golden Delicious' trees, but not on 'Red Delicious' trees. These results show that summer NAA applications can improve the RB of 'Golden Delicious' trees, but caution is needed when planning application on other cultivars, especially on 'Red Delicious' and 'Fuji', due to the pygmy fruit retention problem.

In Experiments 1 and 3, summer ethephon applications promoted RB not only on highly flowering 'Golden Delicious' trees but also on trees with a low flowering intensity, which caused excessive, so-called snowball flowering. These results suggest that flowering-promotion measures with a favourable result on highly flowering trees may enhance the biennial bearing pattern on trees with low flowering intensity. This, and the previously mentioned over-thinning effect on trees with low flowering intensity, shows the importance of considering the physiological status of the individual tree when planning chemical treatment with plant growth regulators in an orchard.

\section{Conclusions}

Presented experiments confirm the ability of summer NAA or ethephon applications to significantly improve the RB of highly flowering 'Golden Delicious' trees and thereby break the biennial bearing pattern, and may be an important tool for improving the profitability of 'Golden Delicious' apple production. However, extending summer NAA application to other apple cultivars is of limited use, due to the problem of NAA fruitlet growth inhibition. As revealed by these experiments applying chemical thinning and flowering-promotion chemicals uniformly in rows with differently flowering trees may unintentionally over-thin and/or excessively promote RB flowering on trees with low flowering intensity and thereby increase the biennial bearing pattern in these trees. Implementation of these results in evolving selective spraying technologies may allow us to standardise flowering and fruiting of trees in orchards using adaptable chemical treatments and thereby additionally optimise apple production in the future. 


\section{References}

Bound, S.A., Jones, K.M., Koen, T.B., Oakford, M.J., Barrett, M.H., and Stone, N.E. (1991). The interaction of Cytolin and NAA on cropping red 'Delicious' apple. J. Hortic. Sci. 66, 559-567. https://doi.org/10.1 $080 / 00221589.1991 .11516184$.

Breen, K.C., Tustin, D.S., Palmer, J.W., Hedderley, D.I., and Close, D.C. (2016). Effects of environment and floral intensity on fruit set behaviour and annual flowering in apple. Sci. Hortic. 210, 258-267. https://doi.org/10.1016/j.scienta.2016.07.025.

Bukovac, M.J., Black, B.L., Hull, J., and Stopar, M. (1994). Interaction between NAA and BA on cropping and fruit size in 'Delicious' and 'Empire' apples. HortScience 29, 472-472. https://doi. org/10.21273/HORTSCI.29.5.472e.

Bukovac, M.J., Sabbatini, P., and Schwallier, P.G. (2006). Modifying alternate bearing of spur-type 'Delicious' apple with ethephon. HortScience 41, 1606-1611. https://doi.org/10.21273/ HORTSCI.41.7.1606.

Bukovac, M.J., Sabbatini, P., Schwallier, P.G., and Schroeder, M. (2008). Characterizing the interaction between NAA and BA on apple fruit abscission and development. HortScience 43, 1794-1801. https:// doi.org/10.21273/HORTSCI.43.6.1794.

Cline, J.A. (2019). Multiple season-long sprays of ethephon or NAA combined with calcium chloride on 'Honeycrisp' apples: I. Effect on bloom and fruit quality attributes. Can. J. Plant Sci. 99, 444-459. https://doi.org/10.1139/cjps-2018-0196.

Davis, K., Stover, E., and Wirth, F. (2004). Economics of fruit thinning: A review focusing on apple and citrus. HortTechnology 14, 282-289. https://doi.org/10.21273/HORTTECH.14.2.0282.

Embree, C.G., Myra, M.T.D., Nichols, D.S., and Wright, A.H. (2007). Effect of blossom density and crop load on growth, fruit quality, and return bloom in 'Honeycrisp' apple. HortScience 42, 1622-1625. https://doi.org/10.21273/HORTSCI.42.7.1622.

Ferree, D.C. (1992). Time of root pruning influences vegetative growth, fruit size, biennial bearing, and yield of 'Jonathan' apple. J. Am. Soc. Hortic. Sci. 117, 198-202. https://doi.org/10.21273/ JASHS.117.2.198.

Goldschmidt, E.E. (2018). An evolutionary platform for alternate bearing in fruit trees. Acta Hortic. 1229, 1-8. https://doi. org/10.17660/ActaHortic.2018.1229.1.

Hočevar, M., Širok, B., Godeša, T., and Stopar, M. (2014). Flowering estimation in apple orchards by image analysis. Precis. Agric. 15, 466-478. https://doi.org/10.1007/s11119-013-9341-6.

Hong, S., Minzan, L., and Qin, Z. (2012). Detection system of smart sprayers: Status, challenges, and perspectives. Int. J. Agric. Biol. Eng. $5,10-23$.

Jones, K.M., Koen, T.B., Bound, S.A., and Oakford, M.J. (1991). Some reservations in thinning 'Fuji' apples with naphthalene acetic acid (NAA) and ethephon. N. Z. J. Crop Hortic. Sci. 19, 225-228. https:// doi.org/10.1080/01140671.1991.10421805.

Jonkers, H. (1979). Biennial bearing in apple and pear: A literature survey. Sci. Hortic. 11, 303-317. https://doi.org/10.1016/03044238(79)90015-3.

Kon, T., and Schupp, J. (2018). Apple crop load management with special focus on early thinning strategies. Hortic. Rev. 46, 255-298. https://doi.org/10.1002/9781119521082.ch6.

Krasniqi, A.L., Damerow, L., Kunz, A., and Blanke, M.M. (2013). Quantifying key parameters as elicitors for alternate fruit bearing in cv. 'Elstar' apple trees. Plant Sci. 212, 10-14. https://doi. org/10.1016/j.plantsci.2013.07.009.
McArtney, S.J., and Unrath, D. (2006). Promotion of flowering in apple with NAA and Ethrel - Oral presentation. HortScience 41, 983. https://doi.org/10.21273/HORTSCI.41.4.983A.

McArtney, S.J., Unrath, D., Obermiller, J.D., and Green, A. (2007). Naphthaleneacetic acid, ethephon, and gibberellin A4 + A7 have variable effects on flesh firmness and return bloom of apple. HortTechnology 17, 32-38. https://doi.org/10.21273/ HORTTECH.17.1.32.

McArtney, S.J., Greene, D., Schmidt, T., and Yuan, R. (2013). Naphthaleneacetic acid and ethephon are florigenic in the biennial apple cultivars Golden Delicious and York Imperial. HortScience 48, 742-746. https://doi.org/10.21273/HORTSCI.48.6.742.

Milyaev, A., Kofler, J., Pfannstiel, J., Stefanelli, D., Flachowsky, H., Hanke, M.V., and Wünsche, J.N. (2018). Histological and proteomic approaches to study floral bud induction in relation to biennial bearing in apple. Acta Hortic. 1229, 277-284. https://doi. org/10.17660/ActaHortic.2018.1229.42.

Robinson, T., Lopez, S., and Lungerman, K. (2010). Chemical thinning and summer PGRS for consistent return cropping of 'Honeycrisp' apples. Acta Hortic. 884, 635-642. https://doi.org/10.17660/ ActaHortic.2010.884.84

Samach, A., and Smith, H.M. (2013). Constraints to obtaining consistent annual yields in perennials. II: Environment and fruit load affect induction of flowering. Plant Sci. 207, 168-176. https:// doi.org/10.1016/j.plantsci.2013.02.006.

Schmidt, T., Elfving, D.C., McFerson, J.R., and Whiting, M.D. (2009) Crop load overwhelms effects of gibberellic acid and ethephon on floral initiation in apple. HortScience 44, 1900-1906. https://doi. org/10.21273/HORTSCI.44.7.1900..

Stefanelli, D., Plozza, T., Flachowsky, H., and Wünsche, J.N. (2018). Young apple tree responses to crop load. Acta Hortic. 1229, 221-228. https://doi.org/10.17660/ActaHortic.2018.1229.34..

Stopar, M. (2004). Thinning of flowers/fruitlets in organic apple production. J. Fruit Ornam. Plant Res. 12, 77-82.

Stopar, M., and Lokar, V. (2003). The effect of ethephon, NAA, BA and their combinations on thinning intensity of 'Summerred' apples. J. Cent. Eur. Agric. 4, 399-404.

Stopar, M., and Tojnko, S. (2005). Small fruit appearance on 'Fuji/M.9' apples thinned by the most known thinning agents. Plant Forsk. 9, $1-4$.

Stover, E., Wirth, F., and Robinson, T. (2001). A method for assessing the relationship between cropload and crop value following fruit thinning. HortScience 36, 157-161. https://doi.org/10.21273/ HORTSCI.36.1.157.

Tromp, J. (2000). Flower-bud formation in pome fruits as affected by fruit thinning. Plant Growth Regul. 31, 27-34. https://doi. org/10.1023/A:1006342328724.

Received: Sep. 22, 2020

Accepted: Dec. 16, 2020

Address of authors:

J. Hladnik and M. Stopar

Department of Fruit Growing, Viticulture and Oenology, Agricultural Institute of Slovenia, Ljubljana, Slovenia 